\title{
'ANUNCIO A V.S. LAS PRESENTES PASQUAS DESEANDO LAS PASE MUY ALBOROZADAS '. CÓMO FELICITAR EN EL SIGLO XVII ${ }^{1}$
}

\author{
MERCEDES ABAD MERINO \\ (Universidad de Murcia)
}

\section{INTRODUCCIÓN.}

En la segunda mitad del siglo XVII, en el mes de diciembre de 1.679, cuando el año está a punto de finalizar, se cumple con la tradición secular de desear unas felices pascuas. Este deseo de felicidad se manifiesta a través de solícitas cartas en las que, tanto quien las envía como quien las recibe y devuelve después la cortesía, muestran algo más que ese loable propósito; ya que reflejan, al mismo tiempo, el grado de estimación social y personal de que gozaban los unos ante los otros.

Esta correspondencia posee unos rasgos comunes que la configuran como un géneroepistolar distinto: el de la FELICITACIÓNNA VIDEÑA, que podría englobarse en el más amplio de la «felicitación escrita». Las felicitaciones aportan una valiosa información acerca de los usos linguísticos e incluso extralinguísticos de la época, y se suman al conjunto de documentos públicos y privados, jurídicos y eclesiásticos, completando el universo de las manifestaciones escritas y añadiendo, así, nuevos aspectos dignos de estudio.

Hemos llamado a estas cartas «documentos» como denominación genérica, tomando la acepción más general de este término, es decir «manifestación escrita con que se prueba o acredita una cosa», sin incluir en ella una finalidad jurídica, aunque

\footnotetext{
${ }^{1}$ Una versión muy resumida del presente artículo fue presentada como comunicación con el título de «'Muy felices y regocijadas pascuas del Santo Nacimiento'. Felicitar en 1.679» en el XXI Simposio dela Sociedad Española de Lingüística, Granada, 1.991.
} 
esta sea la condición imprescindible que, normalmente, los define. Ahora bién, el discurso documental suele estar sujeto a estructuras semejantes y al uso de fórmulas jurídico-literarias que se repiten en cada uno de sus apartados ${ }^{2}$. Por esto - y ese es el propósito de este trabajo - hemos analizado la estructura de las felicitaciones con el fin de comprobar si es común para todas y esta formada por las mismas fórmulas recurrentes, como ocurre en otros tipos de documentos, o si, por el contrario, dado su carácter particular y personal, apenas están sujetas a otras convenciones que las que impone la cortesía y, por lo mismo, convendría incluirlas en otro tipo distinto al de «documentos» tal como los hemos definido y los entiende la diplomática.

\section{2.- DESCRIPCIÓN DEL CORPUS.}

El corpus objeto de estudio está compuesto por veinticinco cartas que abren un libro de Correspondencia recibida de 1.680. Este libro se halla inserto en el de Actas Capitulares del mismo año, perteneciente al Archivo Municipal de Orihuela (A.M.O.) catalogado con la signatura número 151. Se trata de documentos inéditos que hemos transcrito literalmente, desarrollando las abreviaturas, respetando las grafías y normalizando únicamente el uso de mayúsculas y la puntuación según el criterio actual ${ }^{3}$. Han sido numerados del uno al veinticinco, y en los ejemplos damos este número entre paréntesis.

Estos documentos recogen una serie de felicitaciones datadas en diciembre de 1.679 que procuradores, asesores, abogados, síndicos, militares, o incluso el propio obispo de la diócesis,cargos públicos de reconocido prestigio, en suma, envían a los señores justicia y jurados de la ciudad de Orihuela ${ }^{4}$ (en aquellos momentos

2 «El discurso documental, así en su parte central como en las protocolarias, se expresa muchas veces de forma igual o parecida, es decir, con iguales palabras y parecidas frases, plasmadas en fórmulas jurídico-literarias que se repiten para cada clase de documentos, y ello como consecuecia de las siguientes razones:

1" Los documentos son títulos jurídicos que engendran consecuentes derechos y obligaciones y que, por lo mismo, deben estar concebidos y expresados lo más concisa y exactamente posible, con una fraseología ordenada y constante, que no de lugar a subterfugios ni interpretaciones ambiguas dentro del asunto que se trata de documentar.

2" Supuesta esta primera razón y la natural dificultad de mantener siempre esas condiciones de rigor y de precisión en la redacción textual, se explica que los redactores de documentos, en virtud de la ley del menor esfuerzo, amoldaran su estilo a fórmulas más o menos análogas que podían recordar de memoria o tener a mano para su empleo en el momento preciso.

$3^{3}$ Supuestas la naturaleza y el fin de los documentos, resulta normal que las ideas que contienen y los hechos que consignan se repitan con frecuencia, dando pie para que también se repitan las expresiones respectivas.» Paleografía y diplomática,1I. Madrid, U.N.E.D. 1.984, pág.185.

${ }^{3}$ Para más información sobre los criterios de transcripción consúltese el apéndice documental.

${ }^{4}$ La ciudad de Orihuela era la frontera natural entre los reinos de Aragón y Castilla; perteneciente al reino de Valencia, pero más próxima a Murcia que a Alicante, fue una verdadera encrucijada lingüística y cultural. La obra de Juan Bautista Vilar Orihuela una ciudad valenciana en la España moderna . 3 Vols., Patronato Dr. García Rogel; Murcia, 1.981, ofrece una completa revisión histórica y social de la ciudad en la época que estamos estudiando. 
gobernación), máximas autoridades de la ciudad alicantina, desde distintos puntos del Reino de Valencia y aun desde fuera de él, sobre todo desde Madrid y Valencia.

Las cartas no han sido escritas por la mano de quien las envía, sino por su escribano, como evidencian los dos tipos de letra diferentes que aparecen en cada una de ellas: así, lo que podemos llamar el «cuerpo» del documento está escrito con la letra cuidada y soltura propias de un profesional, mientras que sólo la firma y el «besamanos» han sido realizados por el emisor, salvo en el documento 9, en que el firmante ha añadido un mensaje, ajeno a la felicitación, de su propio puño (transcrito con cursiva negrita en el apéndice documental). No es esta una observación gratuita por cuanto el nivel cultural no estaba unido al lugar ocupado en la escala social, y no era difícil que alguno de estos personajes tan sólo supiera firmar.

Habida cuenta que se encuentran en el Libro de correspondencia recibida (único incluido en el de Actas), no aparece ninguna felicitación enviada por la corporación municipal oriolana, aunque tenemos constancia de que las escribía, ya que una parte de las cartas estudiadas constituye la respuesta a felicitaciones escritas previamente. Lo que nos conduce a la siguiente consideración: a pesar de que forman una unidad, podemos clasificar estas felicitaciones, atendiendo a su contenido, en dos tipos:

En el primer tipo incluimos aquellas que felicitan en primer lugar, y que hemos llamado felicitaciones de «IDA», y al segundo grupo pertenecen las antedichas respuestas a otra felicitación previa o felicitaciones de «VUELTA». En todos los apartados hemos tenido en cuenta esta doble división.

\section{3.- ESTRUCTURA.}

La diplomática propone una división de los documentos medievales en los siguientes apartados: exordium, notificatio, narratio, dispositio, sanctio y corroboratio ${ }^{5}$ Cada una de estas partes se repite de forma regular, como hemos visto, por el propio carácter de los textos. Este hecho puede conducir a la conclusión de que cualquier documento que pertenezca a un grupo definido, sea cual sea su naturaleza, estará sometido a una estructuración semejante que lo configure como característico de una clase. Nuestros textos, por otra parte, ni son jurídicos ni medievales, como ya sabemos, pero transmiten una impresión de homogeneidad que nos hace pensar en divisiones del tipo expuesto, aunque la diplomática no considere esta forma epistolar.

5 Díez de Revenga, Pilar: «Análisis de las lexías complejas en documentos medievales murcianos» en Estudios de lingüística Universidad de Alicante, 3, 1.985-86, págs.193-208.

Metzeltin, M: «Segmentation sémantique d'un acte de vente médiéval» en Cahiers de Linguistique Hispaniaue Mediévale, 7-bis. 1.982, págs,141-155. 
En este sentido, hemos distinguido tres partes diferentes características de lo que consideramos una FELICITACIÓN NAVIDEÑA ESCRITA:

\section{PREÁMBULO. \\ 2. FELICITACIÓN. \\ 3. PETICIÓN.}

A estas hay que añadir, además, la despedida, donde se le desean largos años de vida al felicitado; la data, donde aparece el día, mes y año, y el «besamanos», que no hemos estudiado aquí porque las consideramos comunes a todo el género epistolar y no específicas de la modalidad que nos ocupa. No obstante, quedan recogidas en el apéndice documental.

Estos apartados tienen una distribución similar en todos los documentos $\mathrm{y}$, además, cada uno de ellos está constituido por una serie de construcciones y estructuras semejantes que refuerzan esa homogeneidad, como vamos a ver a continuación.

\section{1.- PREÁMBULO.}

Con este nombre designamos la parte que abre el documento y precede al cuerpo central. Puesto que es el primer elemento del disurso funciona también como captatio benevolentiae y es, por tanto, uno de los lugares donde se condensan en mayor número las fórmulas retóricas y de cortesía.

El comportamiento de los textos con respecto a esta parte varía en función del tipo de carta, ya que mientras que en las cartas de «vuelta» este elemento es constante, en las de «ida» puede no aparecer, empezando direcamente con la felicitación o situándose inmediatamente después de aquella. También varía porque los argumentos que se desarrollan en unas y otras son diferentes, aunque persiguen el mismo fin: congraciarse con el receptor.

\subsection{1.- Cartas de «ida».}

Dos son los argumentos que se desarrollan en el preámbulo de estos documentos: la OBLIGATORIEDAD y la RECIPROCIDAD. Ambos están vinculados por una relación causa-efecto, ya que solamente cumpliendo con la obligación de felicitar las pascuas podrá el emisor pasarlas con gusto. Por esta razón, aun cuando no siempre aparecen unidos en el texto, teniendo en cuenta que en la mayoría de los casos sí lo hacen y la estrecha vinculación existente entre ambos, hemos decidido estudiarlos conjuntamente.

\subsubsection{1.- Obligatoriedad.}

Las expresiones empleadas para expresar este concepto responden a los siguientes esquemas: 
V.+Prep.+Pron.+Sust.: «Juzgo en mi obligación» (2)

«Faltara a mi obligación» (3)

V.+Prep.+Pron.+Sust.+Conj.+Adj.+Sust.:

«Corresponde a mi obligación y rendido afecto» (1)

Conj.+Adv.+V.+Prep.+Art.+Sust.:

«Si no cumpliera con la obligación» (8)

Adv.+ V.+Prep.+Pron.+Adj.+Sust.:

«No cumpliera con mi mayor obligación» (7)

Prep.+Sust.+Prep.+Pron.+Sust.: «En cumplimiento de mi obligación» (4)

Se combinan los mismos elementos de tal manera que, pese a responder a un esquema muy parecido, ninguna de las expresiones es igual a otra, aunque todas desempeñan la misma función.

\subsubsection{2.- Reciprocidad.}

Veamos en primer lugar los ejemplos más significativos :

«Para conseguir enteramente la felizidad de las Pasquas del Santo Nacimiento...» (2)

«...que con eso me las prometo con toda felicidad» (5)

«... y para que yo las pase con gusto suplico a vuestra señoría

me participe muy alegres noticias de su salud» (6)

«... para mi será la nueva más regocijada si consiguiere noticias de haverlas vuestra señoría pasado con mucho gusto» (7)

«no pasara con gusto estas Pasquas...» (8)

Como puede apreciarse, no hay ninguna estructura recurrente entre las fórmulas de este apartado. Pero, dejando momentáneamente a un lado la estructura, hay un aspecto destacable en la propia existencia de esta reciprocidad, en su contenido: es el hecho de que felicitar implica la consecución de unas felices pascuas para el emisor y el receptor. Es decir, se realiza algo más que la formulación de un deseo; se realiza un acto de habla, un acto perlocutivo ${ }^{6}$, rasgo éste totalmente perdido en la actualidad en este tipo de discurso. No vamos a profundizar en este tema porque se aparta demasiado del objeto inicial de estudio, pero quede enunciado en virtud de su peculiaridad.

\footnotetext{
${ }^{6}$ Austin, J. L., Cómo hacer cosas con palabras. Barcelona.- Paidós, 1.982 (1Ed. 1.962)., pág. 145: «Hay un tercer sentido $(C)$, según el cual realizar un acto locucionario y con él un acto ilocucionario, puede ser también realizar un acto de otro tipo. A menudo, e incluso normalmente, decir algo producirá ciertas consecuencias o efectos sobre los sentimientos, pensamientos o acciones del auditorio, o de quien emite la expresión o de otras personas, y es posible que al decir algo lo hagamos con el propósito, intencion o designio de producir tales efectos .(...) llamaremos a la realización de un acto de este tipo la realización de un acto perlocutivo o perlocución».
} 


\subsection{2.- Cartas de «vuelta».}

En este tipo de cartas el preámbulo aparece siempre como manifestación de que se ha recibido la felicitación enviada con anterioridad y como expresión del agradecimiento que tal favor comporta. En algunos casos también se comunica que se ha conseguido el efecto deseado o que se desea conseguir el mismo efecto, con lo que, una vez más, nos situamos frente a la antedicha reciprocidad.

Todo un abanico de fórmulas de agradecimiento se abre ante nosotros, y puesto que la razón de tal sentimiento es la felicitación que se ha recibido, se reproduce su contenido, repitiendoel tex to de forma indirecta (reproducción que puede consultarse en el apartado dedicado a la FELICITACIÓN). Veamos las fórmulas a que nos estamos refiriendo y que responden a lo que podríamos considerar el esquema básico, que aparece en el documento 18:

«rezivo su carta y hago la estimación que devo de la merced que me haçe».

\subsubsection{1 - Agradecimiento propiamente dicho.}

Las estructuras giran en torno a tres sustantivos diferentes:

\section{A) RECONOCIMIENTO.}

Prep.+Art.+Part.+Sust.: «Con el debido rreconocimiento...» (10)

Prep.+Art.+Sust.+O.Rel.: «Con el reconocimiento que devo...» (19)

B) ESTIMACIÓN.

$\mathrm{V} .: \ll$ Estimo...» $(14)$

Gerund.: «Estimando...» (16)

Prep.+Adj.+Sust.: «Con mucha estimación...» (12), (25)

Prep.+Art.+Sust.+O. Re.1: «Con la estimasión que devo...» (13)

V.+Adj.+Sust.:«Hago particular estimazión...» (15)

V.+Art.+Sust.+O. Rel.: «Hago particular estimazión...» (15)

C) ALBOROZO.

$$
\begin{aligned}
& \text { Prep.+Adj.+Sust.: «Con summo alboroço...» (11) } \\
& \text { «Con todo alborozo...» (17) } \\
& \text { «Doy a vuestra señoría las gracias ...» (23) } \\
& \text { «Dexame muy favorecido...» (24) }
\end{aligned}
$$

\subsubsection{2.- Deseo conseguido.}

.- Prep.+Art.+Sust.+O.Rel.+V.+Adv.+Adj.:

«Con la merced que vuestra señoría ha sido servido hazerme anunsiándome (...) las he pasado muy gustosas» $(20)$ 
-- Prep.+Sust.+O.Rel.+Pron.+Art.+V.+Adv.+Adj.+Conj.+Adj.:

«Con la merced que vuestra señoría me haze me las aseguro muy alegres y regocijadas» $(22)$

-- Prep.+Art.+Sust.+O.Rel.+Pron.+Art.+V.+Det.+Sust.+Adv.+Adj.:

«Con la merced que en ella me hace he passado estas pasquas muy alegres» (23)

En cuanto a la reciprocidad, no aparece aquí en el preámbulo y tampoco en todos los casos, pero puesto que lo hemos estudiado en este apartado para las felicitaciones de «ida», hagámoslo también para las de «vuelta». En esta ocasión queda aún más clara si cabe la naturaleza perlocutiva a que antes nos refríamos. Sirvan como ejemplo los documentos 20 y 22 :

«Con la merced que vuestra señoría ha sido servido hazerme anunsiandome las Pasquas del Santo Nacimiento de Nuestro Señor Jesuchristo, las he pasado muy gustosas».

«Con la merced que vuestra señoría me haze me las aseguro muy alegres y regosijadas»

$\mathrm{Al}$ ser respuestas, ya se ha logrado el deseo de la felicitación de «ida», y por lo tanto, ya no es obligación escribir, sino cortesía contestar.

\section{2.-FELICITACIÓN.}

Esta es la parte que recoge la esencia y fin de este tipo de cartas; esto es, la expresión del deseo que se quiere transmitir. Constituye lo que podemos llamar «cuerpo central» del documento, ya que suele aparecer inmediatamente después del preámbulo (cuando lo hay) y antes de la petición con que termina el texto.

En todas las felicitaciones analizadas se contempla esta parte, pero no hemos de olvidar en ningún momento que, dada la diferencia existente entre los dos tipos de carta estudiados, la perspectiva desde la que se hace puede ser distinta, ya que unas son cartas de «ida» y las otras son respuestas, por lo que parece oportuno considerar que la intencionalidad de ambas no ha de ser la misma. Las primeras centrarían su interés en manifestar el deseo de que el receptor logre unas felices pascuas, y las segundas añadirán a esto la constancia de que el emisor ha recibido la felicitación que se le envió y él retorna.

Veamos ahora estas expresiones:

- Cartas de «ida».

«El gusto y obsequio con que doy a vuestra señoría las Pasquas del Santo Nacimiento»(1) «Con mi devido rendimiento represento a vuestra señoría mi deseo rogando a Nuestro 
Señor las conceda a vuestra señoría con sumas felizidades y augmentos» (2) «Si (...) dejara de manifestar a vuestra señoría el deseo con que quedo de que vuestra señoría logre muy felices Pascuas de Navidad» (3)

«Anuncio a vuestra señoría con todo gusto las presentes Pasquas (...) por el deseo que me asiste de que vuestra señoría las pase muy alboroçadas» (4)

«desear tenga vuestra merced muy buenas y felices Pasquas del Nacimiento» (5)

«lo mucho que holgaré de que logre tan felices las próximas Pasquas del Santo Nacimiento como se las anuncia mi verdadero afecto» (6)

«si no anunciasse a vuestra señoría las Pasquas del Santo Nacimiento que desseo sumamente logre vuestra señoría con toda felicidad» (8)

«anunciandolas a vuestra señoría muy felizes» (9)

- Cartas de «vuelta».

«(Pasquas) que aya conzedido nuestro señor a vuestra señoría con las felizidades de graçia que su Magestad puede y yo desseo» (10)

«Nuestro Señor las otorgue a vuestra señoría tan felizes y regozijadas» (11)

«mi deseo de que Nuestro Señor se las conceda a vuestra señoría muy felices y gustosas estas y otras muchas» (12)

«que deseo aya pasado vuestra señoría mui gustosas con felises entradas de años» (13) «desseandoselas muy alegres y felices» (14)

«Y olgare las pase vuestra señoría con toda felizidad y el nuevo año, y otros muchos» (15)

«olgare mucho las ayan tenido vuestras mercedes muy alborozadas» (16)

«que desseo pase vuestra señoría muy regocijadas con felices entradas de años» (17)

«deseo que vuestra señoría aya logrado muy caval la felicidad destas Pasquas» (18) «(espero) que se Divina Magestad se las conzeda a vuestra merced con toda prosperidad» (19)

«desseare que vuestra señoría las haya pasado muy felises en este y otros muchos años y que a estas les correspondan los principios de año nuevo con las de reyes con toda felicidad» (20)

«olgareme que vuestra señoría las aia logrado con todo gusto i tenga mui buen fin i prinsipio de año a medida de mi dezeo» (21)

«quedo deseando vuestra señoría las logre con la mayor felizidad a que sigan muy buenos fines y principios de año» (22)

«deseando a vuestra señoría muy buenos años» (23)

«deseando goze muy felizes las de Reyes y entrada de años nuevos, con los augmentos que desseo» $(24)$

« deseo que vuestra señoría las aya gosado muy felices con buen fin y principio de año este y otros muchos» (25) 
Estas cartas de vuelta ofrecen una particularidad importante, y es que, al manifestar que se ha recibido la carta enviada, reproducen el contenido de aquella, con lo que nuestra información se amplía considerablemente, pudiendo así completar el corpus añadiendo una categoría más: Felicitaciones Indirectas.

\section{-Felicitaciones indirectas.}

«buen afesto con que me desea pase estas Pasquas» (10)

«anuncio de las Pasquas del Santo Naçimiento» (11)

«las Pasquas que vuestra señoría se sirbe darme» (12)

«en la ocasión de estas Pasquas del Santo Nasimiento» (13)

«favorecidas memorias en tiempo de Pasquas» (14)

«esperando tener gustosas las buenas Pasquas como me las previene» (15)

«la expressión que me hazen de lo que dessean que logre las Pasquas con toda felizidad» $(16)$

«con ocasión de las Pasquas del Santo Nacimiento» (17)

«se sirve manifestar el desseo que vuestra merced le asiste de que nuestro señor me conzeda estas Pasquas de su Santo Nazimiento con toda felicidad» (19)

«anunsiandome las Pasuas del Santo Nascimiento de nuestro Señor Jesuchristo» (20) «con el feliz anuncio de las Pasquas del Nasimiento de Nuestro redemtor» (21)

«se sirve anunciarme las Pasquas del Santo Nacimiento» (22)

«la memoria de Pasquas con que me honrra» (24)

«se sirve de anunciarme las Pasquas» (25)

\subsection{1.- Estructura.}

Observamos que todas las construcciones responden a la estructura $\mathbf{N}+\mathbf{C D}+\mathbf{C I}$. Ahora bien, este modelo básico dista mucho de ser tan sencillo como el simple esquema podría hacernos suponer, ya que desarrolla sus elementos de forma muy compleja y variada, siendo el C.D. la parte que más se amplía, puesto que, normalmente, recoje la explicitación de la felicitación.

Detengámonos en un análisis pormenorizado de los componentes que nos permitirá comprobar si realmente se puede hablar de estructuras repetidas o lexías desde la concepción de Roudil ${ }^{7}$ o si, por el contrario, lo único que comparten es el esquema valencial ${ }^{8}$ exigido por el contenido semántico de los núcleos verbales.

\footnotetext{
${ }^{7}$ Tal concepción de Roudil se expone en «Du traitement automatique des textes espagnols du Moyen Age à l'analyse sémantique: Une voie plantée d'importants jalons» en Logos Semantikos, Vol.llI . Págs.247-263:

«1\% lorsque deux ou trois unités ne sont employées que réunies, ensemble, sans connaitre isolément d'emploi.

$2^{\circ}$ Iorsque deux ou trois unités sont employées plus fréquentement ensemble qu'isolément, connaissant ainsi un pourcentage élevé d'emploi...»

${ }^{8}$ Seguimos la definición de «valencia verbal» que Tesnière hace en Eléments de syntaxe structurale, Paris; Kincksieck, 1.976. Pág.238: «On peut ainsi comparer le verbe à une sorte d'atome crochu susceptible d'exercer son attraction sur un nombre plus ou moins élevé d'actants, selon qu'il comporte un nombre plus ou moins éleve de crochets que présente un verbe et par conséquent le nombre d'actants qu'il est susceptible de regir, constitue ce que nous appellerous la VALENCE du verbe.»
} 


\subsubsection{1.- Núcleos verbales.}

En las cartas que hemos llamado de «ida» encontramos las siguientes formas verbales:

. «doy» (1)

- «represento» $(2)$

. «(si) dejara de manifestar» (3)

- «anuncio» (4)

.- «desear» $(5)$

.- 《logre» (6)

. $\ll($ no) anunciase» $(7)$

- «anunciarlas» (8)

.- «anunciandolas» (9)

El significado de estos verbos es equivalente; todos pronostican o dan noticia de alguna cosa. Podría sintetizarse esta idea diciendo que todos ellos responden al esquema global:

\section{ANUNCIAR ALGO A ALGUIEN}

Como necesitan obligatoriamente del complemento directo para alcanzar su sentido pleno, hemos situado los núcleos verbales de este elemento,dependientes de un sustantivo como es DESEO, en el mismo nivel que el verbo principal:

(2) «represento»

«mi deseo / $\mathrm{N}^{2} \mathrm{~S}^{\mathrm{or}}$ conceda»

(3) «(si) dejara de manifestar» «el deseo / V.S. logre»

(4) «anuncio» «por el desseo / V.S. las pase»

(7) «(no) anunciasse» «que deseo logre»

Como complementarios de un sustantivo cuyo significado es «anhelo de que acontezca o deje de acontecer algún suceso ${ }^{9}$ no es de extrañar que estas formas se expresen en presente de subjuntivo, tradicionalmente, el modo de la potencialidad por excelencia.

Los núcleos verbales, pues, se sitúan en el campo de la manifestación.

En las cartas que hemos llamado de «vuelta» el núcleo verbal de las estructuras es del tipo «DESEAR», y por tanto, atendiendo al contenido semántico de este verbo, nos encontramos con el esquema:

«DESEAR ALGO A ALGUIEN»

semejante al visto anteriormente y que, como aquel, desarrolla el C.D. ampliamente.

\footnotetext{
${ }^{9}$ D.R.A.E. 1.984
} 
.- «DESEAR» (13), (14), (17), (18), (20), (22), (23), (24), (25)

$.-\ll H O L G A R »(15),(16),(21)$

.- «ESPERAR» $(19)$

El interés se ha desplazado desde el «anuncio» de un deseo al «deseo mismo» que, como en el caso anterior, se complementa con verbos que a la significación del subjuntivo añaden el matiz perfectivo; matiz que se explica simplemente porque las felicitaciones han sido escritas con posterioridad:

.- «aya conzedido» (10)

.- «ayan ttenido» (16)

.- «aya logrado» (18), (21)

- «haya passado» (20)

- «aya gosado» (25)

Finalmente, las felicitaciones «indirectas» inciden en el comportamiento verbal descrito para las cartas de «ida», es decir: el verbo ANUNCIAR aparece con más frecuencia que ningún otro, y en su defecto lo hace el sustantivo ANUNCIO. Sea como fuere, se aprecia que siempre se ha tratado de manifestaciones explícitas a través de verbos de lengua:

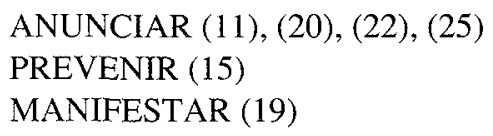

\subsubsection{2.- El complemento directo.}

Vamos a analizar aquí esta función detalladamente, ya que es, como venimos repitiendo, aquella parte expresada con mayor variedad y riqueza de elementos. Estudiaremos, pues, tanto el núcleo o «expresión propiamente dicha» como los modificadores de esta fórmula.

\subsubsection{1.-Núcleo.}

Dos contenidos distintos encierran las expresiones que constituyen el CD de estas felicitaciones: PASCUAS y AÑO NUEVO, dependiendo de la fecha en que hayan sido escritas:

- PASCUAS.

Art.+Sust.: «Las Pasquas» (12),(23),(24), (25)

«Estas Pasquas» (10)

Art.+Adj.+Sust.: «Las presentes Pasquas» (4) 
Sust.+S.Prep.(Prep.+Sust): «Pasquas de Navidad» (3)

Art.+Sust.+Sprep.(Prep.+Art.+Sust.): «Las Pasquas del Nacimiento» (5)

Art.+Sust.+S.Prep.(Prep.+Art.+Adj.+Sust.):

«Las Pasquas del Santo Nacimiento» (1), (7), (6), (11), (13), (17), (19)

Art.+Sust.+S.Prep.(Prep.+Art.+Adj.+Sust.+S.Prep):

«Las Pasquas del Santo Nacimiento de Nuestro Señor Jesuchristo» (20)

Art.+Sust.+S.Prep.(Prep.+Art.+Sust.+S.Prep.):

«Las Pasquas del nacimiento de Nuestro Redemptor» (21)

Estas son, pues, las formas empleadas para expresar ese concepto. En estos ejemplos mejor que en ningunos otros se puede observar el mecanismo de amplificación a partir de una fórmula «tipo» que siguen estras construcciones, y que hemos intentado reflejar disponiéndolas en orden de mayor sencillez a mayor complejidad.

- ANO NUEVO.

Sólo aparece en las cartas de «vuelta» por haber sido escritas con posterioridad y estar más próximas a tal fecha.

Sust:

«años» (23)

Art.+Sust.+Adj.+Conj.+Art.+Adj.:

«El año nuevo y otros muchos» (15)

Sust.+S.Prep.(Prep.+Sust.):

«Entradas de años» (13), (17)

Sust.+Conj.+Sust.+S.Prep.(Prep.+Sust.):

«Fin y principio de año» (21), (25)

«Fines y principios de año» (22)

Sust.+S.Prep.(Prep.+Sust.+Adj.)+S.Prep.(Prep.+Art.+S.Prep.):

«Principios de año nuevo con las de Reyes» (20)

Art.+S.Prep.(Prep.+Sust.)+Conj.+Sust+S.Prep(Prep.+Sust.+Adj.):

«Las de Reyes y entrada de años nuevos» (24)

\subsubsection{2.- MODIFICADORES.}

Vamos a exponer con todo detalle esta parte del C.D. puesto que es la que más fielmente puede reflejar la enorme variedad y riqueza de estas expresiones. Con el 
propósito de hacer más evidente este aspecto, hemos optado por no separar los ejemplos según su estructura, tal como estamos haciendo, sino disponerlos en un solo bloque, lo que facilita la variación.

\section{- PASCUAS}
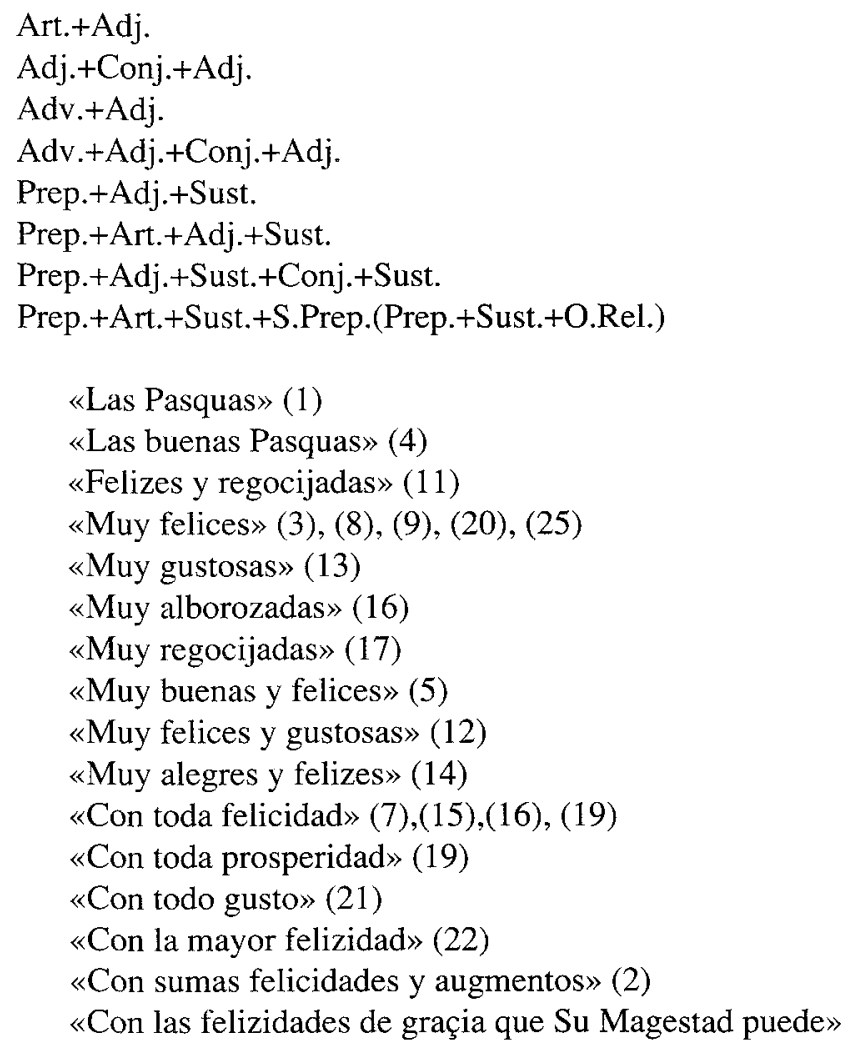

- $A \tilde{N} O$ NUEVO.

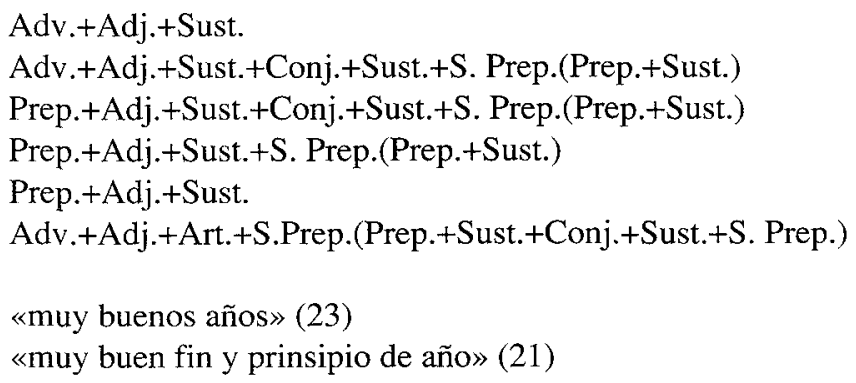


«muy buenos fines y principios de año» (22)

«con buen fin y principio de año» (25)

«con felices entradas de año» (13), (17)

«con toda felicidad» (15), (26)

«muy felices las de reyes y entrada de años» (24)

Vistos todos los ejemplos, sólo cabe concluir que nos encontramos ante una variación asombrosa conseguida con la combinación de los distintos componentes. No hay dos expresiones iguales, ya que si coinciden en el núcleo no lo hacen en los modificadores, y aun en el caso de que tengan los mismos elementos, se conjugan de tal manera que cambia el orden y la disposición. VARIEDAD y VARIACIÓN, pues, a partir de una fórmula básica, como resumen de este inventario.

\section{3.- PETICIÓN.}

Cualquier acto de cortesía estaría incompleto si uno de los interlocutores no se pone al servicio del otro, Estas felicitaciones, como demostraciones corteses que son, no permanecen ajenas a esta consideración y en todas se expresa esa voluntad de servir al felicitado en todo cuanto sea de su gusto.

Hemos llamado «petición» a la parte de las cartas dedicada a este menester y situada normalmente tras la felicitación y antes de la despedida. En las cartas de «ida» aparece siempre, pero no así en las de «vuelta» (los documentos nº 11, 12, 20, 21, 23 y 24 no presentan este elemento).

\subsection{1.- Verbos de la petición.}

Los núcleos verbales de este apartado transmiten un ruego humilde y sumiso, e indican a la vez un deseo vehemente; bien explícitamente a través de los lexemas «suplicar» o «solicitar», bien de forma implícita a través de formas en subjuntivo y en futuro. Veamos los ejemplos más representativos.

-- Explícitos.

«Solicitar» (1)

«Suplicando» (2)

«Espero» (9)

«Deseando» (14), (18)

«Suplico» (6), (10), (17), (25)

\section{- Implícitos.}

«(si) se sirviere» (3)

«me hallara» $(5)$

«(si) mereciere» (7) 
«(si) lograre» (22)

\subsection{2.- Carácter personal.}

Otra particularidad que presenta esta parte es su marcado carácter personal; el emisor aparece explícitamente a través de verbos en primera persona y pronombres que dan testimonio de la no oficialidad de este tipo de mensaje.

- Morfemas verbales.

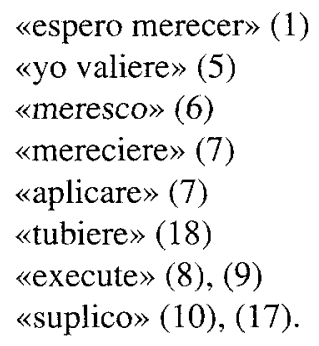

-- Formas pronominales.

$$
\begin{aligned}
& \text { Verbo+Me } \\
& \text { Me+Verbo } \\
& \text { Mi+Adj.+Sust. }
\end{aligned}
$$

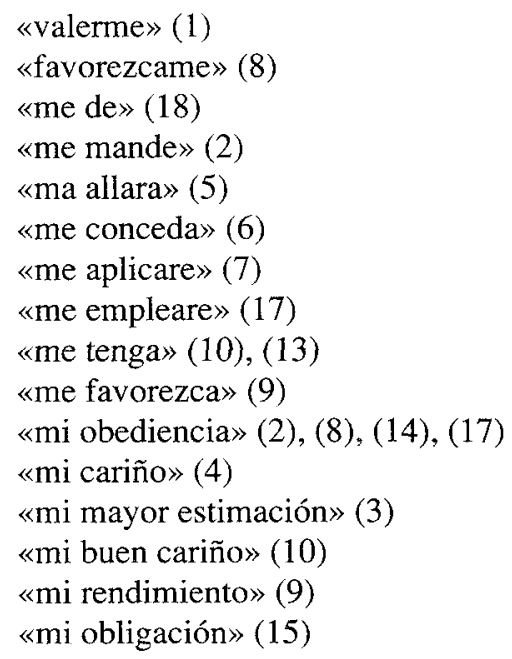

A estas hay que añadir una serie de fórmulas que denotan sumisión y humildad, pero siempre con manifiesto afecto; el emisor se deshace en halagos: 
Prep.+Sust.+S. Prep. (Prep.+Pron.+Sust.)

Prep.+Inf.

Prep.+Rel.+V.+Pron.+Sust.

Prep.+Rel.+Inf.+Pron.+Sust.

Prep.+Adv.+Adj.+Sust.+Conj.+Adj.+Sust.

Prep.+Adj.+Sust.+Conj.+Adj.+Sust.

«para crédito de mi obediencia» (2)

«para obedecerle» (5)

«en que execute mi obediencia» (8)

«en que execute mi rendimiento» $(9)$

«en que manifestar mi obligación» (15)

«con muy buen afecto y fina voluntad» (5)

«con ciega obediencia y rendida voluntad» (7)

«deseando para mi obediencia repetidos empleos» (14)

«mi obediencia estará prompta para todo quanto me empleare» (17)

\section{4.- CONCLUSIONES.}

Una vez revisados los distintos apartados, la impresión inicial de homogeneidad se reduce a eso mismo: una impresión; justificada, eso sí, porque se juega con los mismos elementos, dispuestos en construcciones equifuncionales en cada uno de los bloques que integran este tipo epistolar, que nos muestran hasta dónde se puede llegar combinando unos cuantos elementos constantes.

También hemos podido observar que el acto de felicitar consiste no sólo en anunciar unas felices pascuas, sino también en ponerse al servicio de los felicitados como muestra de estimación y lealtad. Esta prueba de afecto, no obstante, dista mucho de estar redactada según un estilo familiar y desenfadado, como su aparente carácter personal y privado podría hacer suponer, pues son muchas las convenciones motivadas por la cortesía y demás usos sociales que encierra este tipo de discurso.

La ocasión que propicia el envío de la carta, la Navidad, le da a los textos un cierto aire religioso, pero esto no significa que se sirvan de tal lenguaje; antes al contrario, ya que en el lenguaje religioso los sentimientos siempre son sinceros y lo más importante ${ }^{10}$, mientras que en el caso que nos ocupa lo que cuenta es el procedimiento convencional aceptado por todos y basado en la adulación más ostentosa.

${ }^{10}$ Partimos de la concepción de tal lenguaje que Victoria Camps propone en «El lenguaje religioso», Págs. 187-223 del libro Pragmática del lenguaje y filosofía analítica. Barcelona; Península, 1.976: «En nuestra vida cotidiana, el saludar, el dar las gracias, el pedir perdón, suelen ser simples fórmulas de convivencia, más o menos sinceras, según lo exija la stuación en que aparecen. Pero el lenguaje dirigido a Dios no admite dobleces. En el contexto religioso, las convenciones cuentan poco y adquieren gran importancia los sentimientos e intenciones». ( Pág. 193) 
La felicitación es un acto de cortesía en el que se manifiesta el afecto y el respeto que una persona tiene a otra, y subyace el vínculo social que los une. El afecto se anuncia a través de sustantivos como «ESTIMACIÓN», «AFECTO», «CARIÑO» 0 «RENDIMIENTO», y el respeto se amplía a «OBEDIENCIA», y es en este punto donde interviene la mencionada falta de sinceridad, ya que atendiendo a su significado ${ }^{11}$ , «obedecer» es cumplir la voluntad de quien manda; «obediencia ciega» es la que se presta sin examinar los motivos o razones del que manda, y «obediencia debida» la que se rinde al superior jerárquico. Estas expresiones aparecen frecuentemente en las cartas, sin embargo, emisores y receptores gozan del mismo prestigio social y suelen pertenecer , como cargos públicos que son, a los estratos más altos, normalmente caballeros y nobles ${ }^{12}$.

La cortesía, pues, no sólo es una simple muestra de afecto, sino una relación simétrica que se disfraza de reverencialidad según las concepciones de cada época.

En cuanto a la convención, se mantiene la estructura de tres bloques principales repetidos regularmente en cada una de las felicitaciones según los argumentos desarrollados, pero las fórmulas mediante las que estos se expresan intentan no caer en la repetición. Hemos visto, en efecto, una amplia variedad, pero, ¿qué hay detrás de tanta variación?, ¿estamos ante un hecho fortuito o persigue algún fin el que así escribe?.

Quizá la respuesta nos la pueda ofrecer la época misma: estamos en el Barroco ${ }^{13}$, y el autor busca distinguirse de los otros; la originalidad en una ocasión rutinaria y, cómo no, su afirmación como persona culta en consonancia con su tiempo y su clase ( no importa que sea el caballero o el escribano el autor de la carta) a través de léxico seleccionado y un estilo muy cuidado. Aparecen de forma generalizada vocablos como CRÉDITO, FINEZA, ATENTO, que aunque muy corrientes, andaban entonces acreditados en la alta sociedad y en la poesía ${ }^{14}$. El zeugma, por ejemplo, se emplea con gran profusión, signo de lenguaje cultivado y distinguido:

«La ocasión de las Pascuas del Santo Nacimiento me ofrece la de ponerme a los pies de vuestra señoría anunciándolas a vuestra señoría muy felizes» (9)

$"$ D.R.A.E. 1.984.

${ }^{12}$ J.Bautista Vilar, Op.Cit. Vol I Pág. 241: «La inflación de la segunda mitad del XVI, prolongada a la centuria siguiente, mermó los ingresos de la nobleza territorial (...) esa disminución de ingresos, unida a unos gastos de día en día mayores, obligará a los nobles comarcanos a procurarse ingresos adicionales procedentes de oficios concejiles, cargos en las órdenes militares y gubernativos. Estos últimos, salvo excepciones eran reservados a la nobleza regnícola».

13 Hemos seguido la descripción que del lenguaje de la época hace R. Menéndez Pidal en La lengua castellana en el S. XVII. Madrid; Espasa-Calpe, 1.991.

${ }^{14}$ Menéndez Pidal, Op. Cit. Pág. 188 , en el capítulo «Gran innovación en el habla común del S.XVII» Págs.173-191. 
«He rrezibido la carta de vuestra señoría y quedo con el debido rreconoçimiento al buen afesto con que me desea pase estas pasquas, que aya conzedido Nuestro Señor a vuestra señoría con las felizidades de graçia que su Magestad puede y yo desseo, que abiendo cumplido yo con tan debida obligación serán en mi casa tan llenas de felizes suzesos como me promete su buen afesto de vuestra señoría» (10)

«Recibo con summo alboroço el anunçio de las Pasquas del Santo Naçimiento que vuestra señoría me da en su carta, porque vivo seguro de la voluntad con que me las deseara alegres vuestra señoría, de la mía deve asigurarse que corresponde con igual afecto de que Nuestro Señor las otorgue a vuestra señoría tan felizes y regozijadas» (11)

«Estimo las favorecidas memorias que vuestras señorías tienen de mi persona en tiempo de Pasquas que retorno a vuestras señorías desseándosselas muy alegres y felizes» (14)

En resumen, estructuras similares en las que aparecen fórmulas equifuncionales con el grado de lexicalización que implica la repetición de algunos sustantivos y adjetivos de uso obligado, sometidos, constantemente, a numerosas variaciones. Convención y originalidad reunidas, pues, en el mismo texto. Y conformando estas estructuras tal cúmulo de otros elementos de naturaleza semántica, textual, pragmática, social..., tal densidad de relaciones, que nos hacen sospechar que, tal vez, el aspecto estudiado sea el menos significativo.

\section{APÉNDICE DOCUMENTAL.}

A) Criterios de transcripción .-

Los veinticinco documentos han sido transcritos literalmente, respetando las grafías en todos los casos, aunque destacando especialmente los fenómenos de seseo mediante negritas. Se ha normalizado únicamente el empleo de mayúsculas y la puntuación según el criterio actual.

Todas las abreviaturas desarrolladas aparecen en el texto con letra cursiva. Son las siguientes:

B.= Besa.

Dez ${ }^{\circ} /$ Diz $^{\circ} .=$ Diciembre.

Estim $^{\text {on }} .=$ Estimación.

Experi $^{\mathrm{it}}$. = Experimente.

Feli $Z^{\mathrm{d}} .=$ Felicidad.

$\mathrm{G}^{\mathrm{kc}}$. = Guarde.

$\mathrm{Il}^{\mathrm{k}},=$ Ilustre.

$\mathrm{Xatt}^{a}$. = Játiva. 
$\mathrm{L} .=\mathrm{La}$.

M. = Mano.

Magd. = Magestad .

Md. / Mrd. = Merced.

$\mathrm{M}^{\circ}$. = Mayor.

$\mathrm{M}^{\mathrm{s}}$. = Muchos.

Nascim $^{\text {to }}$. = Nacimiento.

$N^{\circ} . S^{o r} .=$ Nuestro Señor.

Oblig" = Obligación.

Occass $^{\mathrm{ex}}$. $=$ Ocasiones

P. $=$ Pie.

Pasq. $=$ Pasquas.

Prinp $^{\circ}$. $=$ Principio.

Q. = Que.

$\mathrm{R}^{\mathrm{vo}}$. = Recivo.

Serv ${ }^{\circ} .=$ Servicio.

$S^{\circ r}$ / $S^{\mathrm{cs}}$. = Señor / Señores. // Servidor.

$\mathrm{S}^{\mathrm{to}}$. = Santo.

Sup $^{\mathrm{co}} .=$ Suplico.

$\mathrm{Val}^{\mathrm{a}} .=$ Valencia.

$\mathrm{Vm} . / \mathrm{Vm}^{*} .=\mathrm{Vuestra}(\mathrm{s})$ Merced(es).

Vi. / VSS. / VSat = Vuesira(s) Senionia(s).

\section{B) Documentos.-}

Doc. 1.

1.679. Diciembre, 14. Xátiva.

A.M.O. Sig. 151. Fol. 293 R.

El gusto y obsequio con que doy a vuestra señoría las Pasquas del Santo Nacimiento, corresponde a mi obligación, y rendido affecto; como el valerme de tan favorable ocasión para solicitar los empleos del servicio de vuestra señoría que espero merecer. Guarde Dios a vuestra señoría mil años. Xáttiva y Diziembre 14 de 1.679.

Besa la mano de vuestra señoría su mayor servidor Carlos Pérez de Sarrión.

Jurados de la ciudad de Orihuela.

Doc. 2.

1.679. Diciembre, 15. Xátiva.

A.M.O. Sig. 15l. Fol. 294 R.

Para conseguir enteramente la felizidad de las Pasquas del Santo Nacimiento juzgo en mi obligación precisso anunciarlas a vuestra señoría. Por lo que con mi devido rendimiento represento a vuestra señoría mi deseo rogando a nuestro señor las conceda a vuestra señoría 
con sumas felizidades y augmentos, y suplicando a vuestra señoría me mande en quanto fuere de su servicio para crédito de mi obediencia. Dios guarde a vuestra señoría los infinitos años que puede y deseo. Xátiva y deciembre 15 de 1.679.

Más cierto y obligado servidor de vuestra señoría El doctor Jayme Pons.

(Muy) nobles y Magníficos Señores jurados de la ciudad de Origuela.

Doc. 3.

1.679. Diciembre, 21. Valencia.

A.M.O. Sig. 151. Fol. 297 R.

Faltara a mi obligación si en ocacion desta Santa celebridad dejara de manifestar a vuestra señoría el deseo con que quedo de que vuestra señoría logre muy felices Pascuas de Navidad, cuya noticia será para mí de particular alboroço mayormente si vuestra señoría se sirviere acompañarla de muchos empleos del servicio de vuestra señoría que han de ser siempre los de mi mayor estimación. Dios guarde a vuestra señoría muchos años como deseo. Valencia y Deziembre a 21 de 1.679.

Don Joseph de Castelví y Alagón.

Besa a vuestra señoría la mano su mayor servidor

Justicia y Jurados de la ciudad de Orihuela.

Doc. 4.

1.679. Diciembre, 21. Valencia.

A.M.O. Sig. 151. Fol. 298 R.

Muy Ilustres Señores.

Anuncio a vuestra señoría con todo gusto las presentes Pasquas en cumplimiento de mi obligación por el desseo que me asiste de que vuestra señoría las pase muy alboroçadas y que sean motivo de los repetidos empleos que solicita mi cariño en servicio de vuestra señoría. Quedo advertido de lo que vuestra señoría me insinúa en su carta de 16 del corriente sobre las letras que han sacado los de Callosa y en passando los feriados se arán las diligencias que convengan, y lo mesmo será en el negocio de los mercaderes que ya se les ha hecho la cominación para que entreguen las letras en poder del escrivano y las ha puesto el procurador y tengo acordadas las nulidades. Quedo a la obediencia de vuestra señoría cuya vida guarde el cielo felizes años como he menester. Valencia y deziembre a 21 de 1.679 .

Besa los pies a vuestra señoría su más reconocido servidor Mathias Albiñana.

Muy Ilustres Señores Justicia y Jurados de la ciudad de Origuela. 
Doc. 5.

1.679. Diciembre, 16. Madrid.

A.M.O. Sig. 151. Fol. 309 R.

Aunque no tengo cosa particular que poner en noticia de vuestra merced, no puedo escusar en mi esta tan precisa obligación, como el desear tenga vuestra merced muy buenas y felices Pasquas del Nacimiento, que con eso me las prometo con toda felisidad, y en quanto yo valiere en servicio de vuestra merced siempre me allará con buen afecto y fina voluntad para obedecerle. Dios guarde a vuestra merced los muchos años que puede y he menester. Madrid y Diziembre a 16 de 1.679 .

Muy Ijustre señor. Besa la mano de vuestra merced su más cierto servidor.

Gerónimo Espuig.

Ilustre señor.

Doc. 6.

1.679. Diciembre, 16. Madrid.

A.M.O. Sig. 151. Fol. 310 R.

Bien creen vuestra señoría de mi fineza lo mucho que holgaré de que logre tan felices las próximas Pasquas del Santo Nacimiento como se las anuncia mi verdaero afecto. Y para que yo las pase con gusto suplico a vuestra señoría me participe muy alegres noticias de su salud y que me conçeda repetidas las órdenes que le meresco de su servicio. Dios guarde a vuestra señoria muchos años. Madrid a 16 de Diciembre 1.679.

Besa la mano de vuestra señoría su mayor servidor

El Obispo de Orihuela.

Ilustres Señores Justicia y Jurados y Racional de la Ciudad de Origuela.

\section{Doc 7.}

1.679. Diciembre, 22. Valencia.

A.M.O. Sig. 151. Fol. 311 R.

No cumpliera con mi mayor obligación si no anunciasse a vuestra señoría las Pasquas del Santo Nacimiento que desseo sumamente logre vuestra señoría con toda felicidad. Para mí será la nueva más regocijada si consiguiere noticias de haverlas vuestra señoría pasado con mucho gusto y mereciere muchos preceptos en el servicio de vuestra señoría a cuya ejecución me aplicaré con ciega obediencia y rendida voluntad. Prospere nuestro señor a vuestra señoría los siglos de que necesito. Valencia y Deziembre 22 de 1.679.

Besa a vuestra señoría sus pies su síndico y muy aplicado servidor Jorge Vicente Sánchez notario.

Señores Jurados de la ciudad de Orihuela. 
Doc. 8.

1.679. Diciembre, 14. Valencia.

A.M.O. Sig. 151. Fol. 326 R.

No pasara con gusto estas Pasquas sino cumpliera con la obligación de anunciarlas a vuestra señoría muy felices. Para que yo las tenga dichosas favorezcame vuestra señoría con los empleos de su mayor servicio en que execute mi obediencia, Dios prospere a vuestra señoría en su mayor lustre como desseo. Valencia y Deziembre 14 de 1.679.

Muy ilustres señores. Besa a vuestra señoría la mano su más obligado servidor y capitán Don Joseph de la Torre y Orumbella.

Ilustres señores justicia y jurados de la ciudad de Orihuela.

Doc. 9.

1.679. Diciembre, 14. Valencia.

A.M.O. Sig. 151. Fol. 327.

Muy ilustres señores

La ocasión de las Pasquas del Santo Nacimiento me ofreze la de ponerme a los pies de vuestra señoría anunciándolas a vuestra señoría muy felizes, y espero me favorezerá vuestra señoría con los empleos de su mayor servicio en que execute mi rendimiento. Dios guarde a vuestra señoría en su mayor lustre como desseo. Valencia y Deziembre 14 de 1.679.

En el negocio que vuestra señoría me mandan el doctor Domingo Ruiz, como en quantos fueren de su agrado, servirá a vuestra señoría con las veras de mi obligación.

Muy ilustres señores. Besa a vuestras señorías la mano su más obligado y reconocido servidor Juan de la Torre y Orumbrella.

Ilustres señores justicia y jurados de la ciudad de Orihuela.

Doc. 10.

1.679. Diciembre, 21.Valencia.

A.M.O. Sig. 151. Fol. 301 R.

He rrezebido la carta de vuestra señoría y quedo con el debido rreconocimiento al buen afesto con que me desea pase estas Pasquas que aya conzedido nuestro señor a vuestra señoría con las felizidades de graçia que su Magestad puede y yo desseo, que habiendo cumplido yo con tan debida obligación, serán en mi cassa tan llenas de felizes suzesos como me promete su buen afesto de vuestra señoría y le supplico me tenga muy ocupado en cosas de su mayor agrado para que experimente mi buen cariño. Guarde Dios a vuestra señoría los i que puede. Valencia y Diziembre 21 de 1.679.

Besa la mano de vuesta señoría su más seguro servidor. 
Doc. 11.

1.679. Diciembre, 21. Valencia.

A.M.O. Sig. 151. Fol. 302 R.

Recibo con summo alboroço el anunçio de las Pasquas del Santo Naçimiento que vuestra señoría me da en su carta, porque vivo seguro de la voluntad con que me las deseará alegres vuestra señoría. De la mía deve asigurarse que corresponde con igual afecto de que Nuestro Señor las otorgue a vuestra señoría felizes y regozijadas, y prospere a vuestra señoría tan dilatados siglos como puede y se lo suplico. Valencia y 21 de Deziembre de 1.679.

Besa la mano de vuestra señoria su más rendido servidor Donato Sánchez del Castellar.

Señores justiçia y jurados de la çiudad de Orihuela.

Doc. 12.

1.679. Diciembre, 21. Valencia

A.M.O. Sig. 151. Fol. 303 R.

Con mucha estimación recibo las Pasquas que vuesta señoría se sirbe darme, y puedo asegurarle de que mi afecto le mereçe esta demostración de su fineza. Y también mi deseo de que Nuestro Señor se las conceda a vuestra señoría muy felices y gustosas estas y otras muchas y guarde a vuestra señoria con toda prosperidad. Valencia y Deciembre 21 de 1.679.

Besa la mano de vuestra señoría su mayor servidor.

Don Francisco $\mathrm{y}$

Justicia y jurado de la ciudad de Origuela.

Doc. 13.

1.679. Diciembre, 21. Valencia.

A.M.O. Sig. 151. Fol. 304 R.

Resibo su carta de vuestra señoría con la estimasión que devo a la mersed que me ase en la ocasión de estas Pascuas del Santo nasimiento que deseo aya pasado vuestra señoría mui gustosas con felises entradas de años y queme tenga en memoria para mandarme en su servisio. Guarde Dios a vuestra señoría muchos años Valensia y desiembre 21 de 1.679.

Besa la mano de vuestra señoría su mayor servidor Don Antonio Milán y de Aragón

Justicia y jurados de la ciudad de Origuela. 
Doc. 14 .

1.679. Diciembre, 25. Alicante.

A.M.O. Sig. 151. Fol. 305 R.

Muy Ilustres Señores

Estimo mucho las favorecidas memorias que vuestras señorías tienen de mi persona en tiempo de Pasquas, que retorno a vuestras señorias desseándoselas muy alegres y felizes; y para mi obediencia repetidos empleos en que manifestarle esta verdad. Guarde nuestro Señor a vuestras señorías muy dilatados años. Alicante y Deziembre 25 de 1.679.

Don Francisco Guerau y Ciurana.

Ilustres señores

Doc. 15 .

1.679. Diciembre, 23. Madrid.

A.M.O. Sig. 151. Fol. 307 R.

En todas ocasiones experimento la atensión de vuestra señoría; de que to hago particular estimazión, esperando tener gustosas las buenas Pasquas como me las previene en su carta de 12 de este. Y olgaré las pase vuestra señoría con toda felizidad y el nuevo año, y otros muchos que para mí lo serán siempre que tuviere ocasiones en que manifestar mi obligación a vuestra señoría, que guarde Dios mil años. Madrid 23 de Diciembre 1.679.

El Duque de Arcos y de

Ciudad de Orihuela.

Doc. 16.

1.679. Diciembre, 28. Valencia.

A.M.O. Sig. 151. Fol. 312 R.

Muy bien deben vuestras mercedes a mi buena volunttad la expressión que me hazen de lo que dessean que logre las Pasquas con ttoda felizidad, y estimándoles estte buen anunzio holgaré mucho las ayan ttenido vuestras mercedes muy alvorozadas, como que se ofrezcan ocassiones en que manifesttarles quantto desseo su mayor sattisfazión y que guarde Dios a vuestras mercedes largos años. Real de Valenzia 28 de diciembre de 1.679. 
Doc. 17.

1.679. Diciembre, 23. Madrid.

A.M.O. Sig. 151. Fol. 313 R.

Con todo alborozo me dexa la carta de vuestra señoría que logro con fecha de 12 del corriente, quedando muy reconocido al favor que vuestra señoría me haze con ocasión de las Pasquas del Santo Nascimiento que desseo pase vuestra señoría muy regocijadas con felices entradas de años, y suplico a vuestra señoría no escuse de mandarme quanto sea de su servicio, pues mi obediencia estará prompta para todo quanto me empleare vuestra señoría como lo experimentará siempre. Dios guarde a vuestra señoría como se lo suplico. Madrid a 23 de Deziembre 1.679 .

Besa la mano de vuestra señoría su mayor servidor

Don Gerónimo Dalmau y _ـ____.

Justicia y jurados de la ciudad de Orihuela.

Doc. 18.

1.679. Diciembre, 27. Madrid.

A.M.O. Sig. 151.Fol.315 R.

Recivo su carta de vuestra señoría y ago la estimacion que devo de la merced que me haçe, y deseo que vuestra señoría aya logrado muy caval la felicidad de estas Pasquas y que me de muchas occasiones en que manifestar mi deseo de servirle. Guarde Dios a vuestra señoría muchos años como deseo. Madrid a 27 de Diçiembre se 1.679.

El Marqués de Castelnovo.

Señores justicia y jurados de la ciudad de Origuela.

Doc. 19.

1.679.Diciembre, 27. Madrid.

A.M.O. Sig. 151. Fol. 316 R.

Señor mío con el reconocimiento que devo recivo su carta de vuestra merced en que se sirve manifestar el desseo que a vuestra merced le asiste de que nuestro señor me conzeda estas Pasquas de su Santo Nazimiento con toda felicidad. Estoy mui asegurado de su afecto de vuestramerced y de la merced que siempre me hace y espero con ella lograrlas dichosas y que su Divina Magestad se las conzeda a vuestra merced con toda prosperidad de que me alegraré sumamente como de berme muy empleado en serbir y obedezer a vuestra merced, cuia vida guarde Dios muchos años como desseo. Madrid a 27 de Diciembre de 1.679.

Muy siguro servidor de viestra merced que su mano besa. Don Miguel de Galba y de

Jurados de la ciudad de Origuela. 
Doc. 20.

1.679. Diciembre, 28. Valencia

A.M.O. Sig. 151. Fol. 318 R.

Con la merced que vuestra señoría a sido servido hazerme anunsiandome las Pasquas del Santo Nascimiento de Nuestro Señor Jesuchristo, las he passado muy gustossas. Dessearé que vuestra señoría las haya passado muy felises en este y otros muchos años y que a estas les correspondan los principios de año nuevo con las de Reyes con toda felicidad. Dios nuestro señor guarde a vuestra señoría como desseo. Valencia 28 de Deziembre de 1.679.

Besa la mano de vuestra señoría su más cierto y mayor servidor. Don Jayme de

Señores jurados de la ciudad de Origuela.

Doc. 21.

1.679. Diciembre, 28. Valencia.

A.M.O. Sig 151. Fol. 319 R.

Resibo su carta de vuestra señoría de 16 de los corrientes con el feliz anuncio de las Pasquas del Nasimiento de Nuestro Redemtor. Olgareme que vuestra señoria las aia logrado con todo gusto i tenga mui buen fin i prinsipio de año a medida de mi deseo. Dios guarde a vuestra señoría. Valencia i Desiembre a 28 de 1.679.

Mayor servidor de su señoría que su mano besa Francisco Valero

Señores justicia y jurados de la cidad de Origuela.

Doc. 22.

1.679. Diciembre, 28. Valencia.

A.M.O. Sig. 151. Fol.320 R.

Recibo su carta de vuestra señoría de - de los corrientes, en que se sirve anunciarme las Pasquas del Santo Nacimiento, y con la merced que vuestra señoría me haze me las eseguro muy alegres y regosijadas, y quedo deseando vuestra señoría las logre con la mayor felizidad a que sigan muy buenos fines y principios de año, que para mí lo serán si en ellos lograre muchos empleos de su agrado de vuestra señoría, que guarde el cielo muchos años como deseo. Valencia y Deziembre 28 de 1.679.

Besa la mano de vuestra señoría su más siguro servidor Don Francisco Ortín Luquí

Señores jurados de la ciudad de Origuela. 
Doc. 23.

1.679. Diciembre, 28. Valencia.

A.M.O. Sig.151. Fol. 321.

Recibo su carta de vuestra señoría y con la merced que e ella me hace he passado estas Pasquas muy alegres. Doy a vuestra señoría las gracias por lo que me favorece y le retorno el cumplimiento, deseando a vuestra señoría muy buenos años, y que nuestro Señor guarde a vuestra señoría los muchos que puede. Valencia y Diciembre a 28 de 1.679.

Besa la mano de vuestra señoría su mayor servidor El Doctor Isidoro Aparicio Gilart.

Justicia y jurados de la ciudad de Orihuela.

Doc. 24.

1.679. Diciembre, 26. Valencia.

A.M.O. Sig.151. Fol. 322 R.

Déxame muy favorezido la memoria de Pasquas con que vuestra señoría me honrra en las del Nazimiento de Nuestro Señor que retorno a vuestra señoría con muy buena voluntad, desseando goze muy felizes las de Reyes y entrada de años nuevos, con los augmentos que desseo. A vuestra señoría guarde nuestro Señor muchos años, de Valencia Deziembre 26 de1.679.

Besa la mano de vuestra señoría su mayor servidor Don Diego Descals y Salcedo.

Señores justicia y jurados de la ciudad de Origuela.

Doc. 25.

1.679. Diciembre, 27. Madrid.

A.M.O. Sig. 151. Fol. 328 R.

Con mucha estimación recibo la de vuestra señoría en que se sirve de anunciarme las Pasquas. Deseo que vuestra señoría las aya gosado muy felices con buen fin y principio de año este y otros muchos, y le suplico me de muchos empleos de su serbicio. Dios prospere a vuestra señoría como deseo. Madrid y Diziembre 27 de 1.679.

Besa la mano de vuestra señoría su mas cierto servidor Don Lorenzo Matheu y Sans

Señores justicia y jurados de Origuela. 